\title{
NOVAS MANEIRAS DE ENSINAR E APRENDER: o caso da disciplina Prática Projetual em Design de Ambientes
}

\author{
Paula Glória Barbosa \\ Escola de Design - Universidade do Estado de Minas Gerais \\ paulaglbarbosa@gmail.com \\ Bárbara Lima Maciel \\ Escola de Design - Universidade do Estado de Minas Gerais \\ barbaralmaciel@yahoo.com.br \\ Samantha Cidaley de Oliveira Moreira \\ Escola de Design - Universidade do Estado de Minas Gerais \\ samanthacidaley@gmail.com
}

\begin{abstract}
Resumo: Este artigo visa a apresentar prática pedagógica vivenciada em 2012 na disciplina Prática Projetual-I do curso de Design de Ambientes da Escola de Design da Universidade do Estado de Minas Gerais. Essa prática foi desenvolvida a partir da identificação, por parte dos professores, das mudanças no comportamento dos alunos, da diversidade de demandas na contemporaneidade e do comportamento do mercado de design, que exige postura proativa e conduta empreendedora. Com o objetivo de responder às expertises desejadas para o designer, a partir do conteúdo apresentado no Projeto Pedagógico da Escola de Design (2003) e nas reflexões de Rafael Cardoso (2012), a prática proposta buscou sensibilizar, conscientizar e capacitar os alunos para o desenvolvimento de soluções de design para ambientes diversos na cidade de Belo Horizonte. Para tanto, buscou-se referências sobre o pensamento reflexivo de John Dewey (1979) e na ideia de uma pedagogia da autonomia de Paulo Freire (2013). A pesquisa-ação exercida e registrada neste artigo identificou tal prática como processo importante aos alunos na compreensão de seu papel social, como exercício da metodologia de projeto de design e como oportunidade para desenvolver visão sistêmica. Esse processo fortaleceu a importância do trabalho coletivo entre professores e da sistematização do conhecimento que produzem, evidenciando ainda a necessidade de revisão periódica das práticas pedagógicas e da didática como premissa para avanços no ensino e aprendizado do design.
\end{abstract}

Palavras-chave: design de ambientes, prática pedagógica, pensamento reflexivo, pedagogia da autonomia, ensino-aprendizagem em design. 


\begin{abstract}
This article aims to present the pedagogical practice experienced on the discipline Prática Projetual-I of the Interior Design course at the Design School of the University of the State of Minas Gerais. This practice was developed based on the identification, on behalf of the teachers, of changes in students' behavior, the diversity of the contemporary demands and the behavior of the design market, that requires a more proactive and entrepreneurial conduct. With the objective of answering the interior designer's expertise from the content presented by the School of Education Program Design (2003) and the reflections presented by Rafael Cardoso (2012), the proposed activity tried to touch, to make the students aware of and able to develop solutions for various environments in Belo Horizonte. To this end, references about John Dewey's (1979) reflective thought were searched for, and the idea of a pedagogy autonomy of Paulo Freire (2013). The action-research exercised in this article identified this practice as an important process for the students to understand their social role, as an exercise in design's project methodology and as an opportunity to develop a systemic view. The highlighted process strengthen the sense of collective work among professors and the importance of the knowledge they produce, evidencing the necessity of periodic review of the educational practices as a premise for advances in teaching and learning design.
\end{abstract}

Key-words: Interior Design, pedagogical practice, reflective thought, pedagogy autonomy, teach-learn design.

\title{
1. INTRODUÇÃO
}

Este trabalho visa a apresentar prática pedagógica vivenciada entre os meses de abril e junho de 2012, pelo grupo de professores e alunos da disciplina Prática Projetual-I, no 3 o período do curso de Design de Ambientes da Escola de Design (ED) da Universidade do Estado de Minas Gerais (UEMG).

A graduação em Design de Ambientes da UEMG, cuja origem está no curso de bacharelado em Decoração oferecido pela instituição desde a década de 1960, está em atividade desde 2004 com a vigência de um novo Projeto Pedagógico, revisto e modificado para adequação à proposta do design (ESCOLA DE DESIGN, 2003). O design, naquele momento, assumia lugar de evidência na sociedade brasileira devido, principalmente, ao seu caráter interdisciplinar e à sua capacidade de articular criativamente os aspectos estéticos, funcionais e simbólicos do contexto de projeto.

As soluções em design cabem às diferentes demandas da contemporaneidade, e podem atingir os objetos, os processos, os serviços e seus respectivos sistemas, que 
num contexto amplo estão inseridos e fazem parte do ambiente ${ }^{1}$. O design para ambientes apresenta-se, assim, como uma atividade voltada para a solução de "problemas" das pessoas em relação ao meio no qual estão inseridas. Tanto o arranjo quanto a ambiência dos ambientes são meios para a apresentação de solução em design, qualificando o uso das edificações, reduzindo a percepção dos não lugares, estimulando a convivência, facilitando a percepção de tempo e de espaço pelos usuários, construindo sentidos e concretizando desejos. Assim, cabe ao profissional designer de ambientes desenvolver propostas para os desafios relativos ao cotidiano, correspondendo às necessidades e às possibilidades dos indivíduos, promovendo melhor apropriação do lugar, bem estar e qualidade de vida aos usuários.

Conforme o Projeto Pedagógico vigente, o principal objetivo do curso de Design de Ambientes da ED/UEMG é formar profissionais capazes de delinear os processos e as ferramentas de design, tanto na atividade projetual quanto na identificação e antecipação de problemas de design, para promoção do bem estar físico, econômico e social dos usuários de seu objeto de trabalho. Nesses termos, a formação do designer de ambientes, egresso desse curso, deve ser pautada na construção de conhecimentos e no desenvolvimento de habilidades e competências ${ }^{2}$ que o permita cumprir com os objetivos postulados em sua atuação profissional.

A partir do conteúdo apresentado pelo Projeto Pedagógico da Escola de Design (2003) e das reflexões propostas por Cardoso (2012), acredita-se que sejam habilidades e competências inerentes à atuação do designer: 1) a capacidade criativa, referente à proposição de soluções inovadoras a partir do domínio das técnicas de criação; 2) o domínio da linguagem, que compreende a habilidade instrumental, técnica e expressiva para a comunicação de ideias, a partir do uso de diferentes mídias (escrita, fala e visual) e por meio de diversos recursos (manuais ou computacionais); 3 ) o trânsito interdisciplinar, relacionado à capacidade de dialogar com diferentes áreas do conhecimento e à atuação em equipes multidisciplinares de desenvolvimento de pesquisa e projeto; 4) a visão holística, traduzida, também, como a visão sistêmica do projeto, que trata da capacidade de articular os elementos da cultura humana e material na proposição de soluções inovadoras, bem como a capacidade crítica para gerenciar os processos de design; 5) o domínio da metodologia projetual, referente à capacidade de trabalhar com fluidez entre as etapas que compreendem a metodologia de desenvolvimento de projeto; 6) a conduta empreendedora, no que se refere ao entendimento da linguagem de gestão e da capacidade de identificar oportunidades

\footnotetext{
${ }^{1}$ Sabe-se que o termo ambiente é amplo e utilizado em diversas ciências (humanas, sociais aplicadas, exatas, biológicas) e no senso comum utilizado como sinônimo de espaço, meio ou lugar onde existem, vivem e convivem os seres vivos. Neste artigo, considera-se que um ambiente é constituído pelas condições materiais (recursos naturais, humanos, financeiros, técnicos e tecnológicos, espaço disponível e sistema de objetos) e imateriais (percepção, satisfação, expectativa, apropriação, experimentação, relação, convívio, tempo e interação) necessárias para que as pessoas desenvolvam suas atividades individuais e coletivas, nos âmbitos cultural, social, econômico e político de sua existência. Os ambientes podem acontecer para finalidades diversas, dentre outras, para morar, comercializar, passear, aprender, rezar/orar, exercitar, pesquisar, encontrar, trabalhar, inovar.

${ }^{2}$ Sobre competência, Machado apud Perrenoud et al. ( 2002, p.145) defende que esta "está sempre associada a uma mobilização de saberes. Não é um conhecimento 'acumulado', mas a virtualização de uma ação, a capacidade de recorrer ao que se sabe para realizar o que se deseja, o que se projeta." Por sua vez, "as formas de realização das competências foram chamadas habilidades." Noutros termos, "é como se as habilidades fossem microcompetências, ou como se as competências fossem macrohabilidades. Para desenvolver as habilidades, recorre-se às disciplinas que são apenas meios para isso."
} 
de negócio frente ao cenário em que atua; 7) a percepção aguçada, ou seja, a capacidade de decodificação de informações; 8 ) a abertura à pesquisa, referente à erudição, ao repertório, principalmente cultural, e à capacidade de pesquisar, permitindo a condição de sustentar as suas ações e questioná-las; e 8) a visão espacial, que compreende a capacidade de pensar em três dimensões.

Fundamentado na relação entre ensino, pesquisa e extensão, o curso de Design de Ambientes da Escola de Design dispõe de 3.204 horas/aula divididas em quatro modalidades de atividades: os conteúdos obrigatórios, os conteúdos optativos, o estágio supervisionado e as atividades complementares. Dentre as disciplinas obrigatórias está a Prática Projetual, presente em seis períodos (do 3o ao 8a períodos) e cuja ementa trata do "planejamento e desenvolvimento de projetos de várias complexidades como instrumento para experimentar e verificar metodologias e aplicações tecnológicas" (ESCOLA DE DESIGN, 2003, p.52).

O exercício da disciplina Prática Projetual-I, primeiro contato do aluno com a atividade de projeto, consiste na convergência de teorias ${ }^{3}$ oferecidas no primeiro ano de curso, no embasamento metodológico do design ${ }^{4}$ e na experimentação de atividades práticas, consideradas de baixa complexidade. Há anos, durante o semestre letivo, foi usual o desenvolvimento de dois trabalhos práticos - um residencial e outro comercial - em que, como tentativa de simplificar o processo, o professor definia o contexto projetual ${ }^{5}$ e estimulava o curso das etapas de projeto de maneira linear.

Pela necessidade de instigar a curiosidade e a capacidade investigativa, e de identificar e induzir demandas de design, ou seja, enxergar possibilidades e empreender o design de ambientes, durante o primeiro semestre do ano 2012, os professores responsáveis pela disciplina Pratica Projetual-I decidiram algumas alterações na prática pedagógica, bem como na didática. A reflexão crítica se deu vistas as mudanças no comportamento dos alunos, a diversidade de demandas pela sociedade na contemporaneidade e os novos desafios e expectativas em relação a contextos múltiplos num futuro próximo, sem falar no comportamento do mercado de trabalho para o design que exige postura proativa e conduta empreendedora.

Dalben e Castro (2010, p.55) sinalizam que as mudanças sociais, articuladas aos interesses da escola e dos professores no trabalho em prol do bom funcionamento da instituição, impulsionam a "dinâmica do processo educativo" com o pensamento focado, dentre outras questões, nos novos "métodos, estratégias e procedimentos de ensino mediados por uma relação pedagógica eficaz, que promova o crescimento e o aprimoramento do aluno". Desse modo, e pensando sobretudo no desenvolvimento das habilidades e competências dos alunos de design, idealizou-se uma prática pedagógica diferenciada da exercida até então. Afinal, é preciso desenvolver "novas formas de aprender, de conviver, de exercer a cidadania e de relacionar-se com a sociedade" (DALBEN; CASTRO, 2010, p.55).

\footnotetext{
3 Psicologia, Percepção e Forma; Comunicação e Semiótica; História Crítica da Arte e do Design; Expressão Gráfica; Representação Técnica; Fatores Filosóficos, Sociológicos e Culturais; Metodologia Científica; Metodologia Aplicada; Processos de Criação.

${ }^{4}$ No curso de Design de Ambientes da Escola de Design/UEMG, as principais referências para a metodologia do design são: Löbach (2001), Baxter (2005), Bürdek (2006) e Munari (2008).

${ }^{5}$ Até esse trabalho, era o professor o responsável por apresentar aos alunos a demanda, a planta arquitetônica, o negócio, a localização, o cliente, o publico, dentre outras informações necessárias ao briefing.
} 
Para isso, os professores buscaram fundamentação no estudo sobre o pensamento reflexivo de John Dewey (1979) e na pedagogia da autonomia de Paulo Freire (2013) para desenvolverem prática composta de atividades desafiantes e instigantes, que proporcionassem aos alunos a oportunidade de experimentar a realidade projetual e exercitar a reflexão nas etapas de desenvolvimento de uma proposta de design de ambientes, e aos próprios professores, uma análise crítica sobre a sua própria atuação na aprendizagem.

Para estruturação do presente trabalho, as autoras utilizaram a pesquisa-ação. Trata-se de pesquisa que utiliza a prática como concretizadora das questões teóricas, ampliando a compreensão do assunto. Para Thiollennt (1996),

[...] a pesquisa-ação é um tipo de pesquisa social com base empírica, que é concebida e realizada em estreita associação com uma ação ou com a resolução de um problema coletivo e no qual os pesquisadores e os participantes representativos da situação ou do problema estão envolvidos de modo cooperativo ou participativo. (THIOLLENT, 1996, p.14)

Complementando, Tripp (2005, p.445) menciona que, em educação, a pesquisa-ação é compreendida como estratégia para o "desenvolvimento de professores e pesquisadores de modo que eles possam utilizar suas pesquisas para aprimorar seu ensino e, em decorrência, o aprendizado de seus alunos". Assim, através dessa modalidade de pesquisa, foi possível refletir, aplicar e verificar a prática proposta que será descrita detalhadamente nos próximos tópicos.

\section{REFLEXÃO E AUTONOMIA COMO PRINCÍPIOS NORTEADORES NO PROCESSO DE ATUALIZAÇÃO DAS PRÁTICAS PROJETUAIS EM DESIGN PARA AMBIENTES}

No relatório sobre educação para o século XXI, realizado para a UNESCO em 2010, o economista Jacques Delors, coordenador do documento, chama a atenção para o fato de que os quadros tradicionais da existência humana sofreram profunda modificação nos últimos tempos, fortalecendo a necessidade de "compreender melhor o outro e o mundo" (UNESCO, 2010, p.13). Assim, a equipe responsável pelo relatório idealizou o termo "educação criativa", que serviu de suporte à uma nova mentalidade apoiada no princípio do aprender a conviver, "desenvolvendo o conhecimento a respeito dos outros, de sua história, tradições e espiritualidade". Além desse, outros três pilares sustentam a concepção de educação para o futuro: aprender a conhecer, aprender a fazer e aprender a ser. Afinal,

[...] com o desenvolvimento da sociedade da informação e a multiplicação das possibilidades de acesso a dados e fatos, a educação deve permitir que todos possam coletar, selecionar, ordenar, gerenciar e utilizar esse volume de informações e servir-se dele. (UNESCO, 2010, p. 14).

Correspondendo às orientações para a educação para o século XXI, os professores da disciplina Prática Projetual-I adotaram a capacidade de reflexão e a autonomia como atitudes essenciais nos processos de ensino e aprendizado do design.

John Dewey foi pioneiro ao elucidar o uso da reflexão como instrumento de aprendizagem. De acordo com o autor, o pensamento reflexivo é "a espécie de pensamento que consiste em examinar mentalmente o assunto e dar-lhe consideração séria e consecutiva" (DEWEY, 1979, p.13). É aquele que surge através de um problema 
ou situação obscura que requer esclarecimento. Logo, trata-se de um pensamento intencional gerenciado e não regido apenas pelo acaso ou pelo intuitivo e rotineiro método de associação de ideias. Diferencia-se de um pensamento comum, principalmente, por possuir "unidades definidas, ligadas entre si de tal arte que o resultado é um momento continuado para um fim comum" (DEWEY, 1979, p.14).

Para pensar verdadeiramente bem, ou seja, reflexivamente, é necessário prolongar o estado de dúvida. A dúvida torna-se, então, o estímulo essencial para uma investigação perfeita, "na qual nenhuma ideia se aceite, nenhuma crença se afirme positivamente, sem que se Ihes tenham descoberto as razões justificativas" (DEWEY, 1979, p.25).

O filósofo ainda esclarece três justificativas para o pensamento reflexivo ter uma finalidade educacional: a primeira é que ele liberta o homem do pensar rotineiro, tornando-o capaz de projetar e planejar realidades futuras; a segunda é que o pensamento reflexivo possibilita o preparo e a invenção sistemáticos, transformando o homem em ser capaz de aperfeiçoamento, de antecipar resultados, sejam positivos (para concretizá-los) ou negativos (para evitá-los); e a terceira é que o pensamento reflexivo atribui significados, o que enriquece o mundo com novos pontos de vista, com novos valores.

Para Dewey (1979, p.109) o processo de formar a suposta solução "é constantemente confrontado com as condições observadas como realmente presentes". Assim, para ser um pensador reflexivo é necessário possuir três atitudes: a mentalidade aberta - ausência de preconceitos e hábitos que limitem a mente e impeçam de visualizar novas oportunidades e novas ideais, junto a um desejo ativo de absorver mais informações de diferentes fontes e de reconhecer as possibilidades de erros; a responsabilidade intelectual - considerar as consequências de cada passo projetado assegurando a integridade, coerência e harmonia do que se defende; e o envolvimento de todo o coração - para manter-se disposto e focado na causa (DEWEY, 1979).

Nesse contexto, o pensamento reflexivo é estruturado em cinco fases ou etapas não lineares e flexíveis, como demonstra a Figura 1.

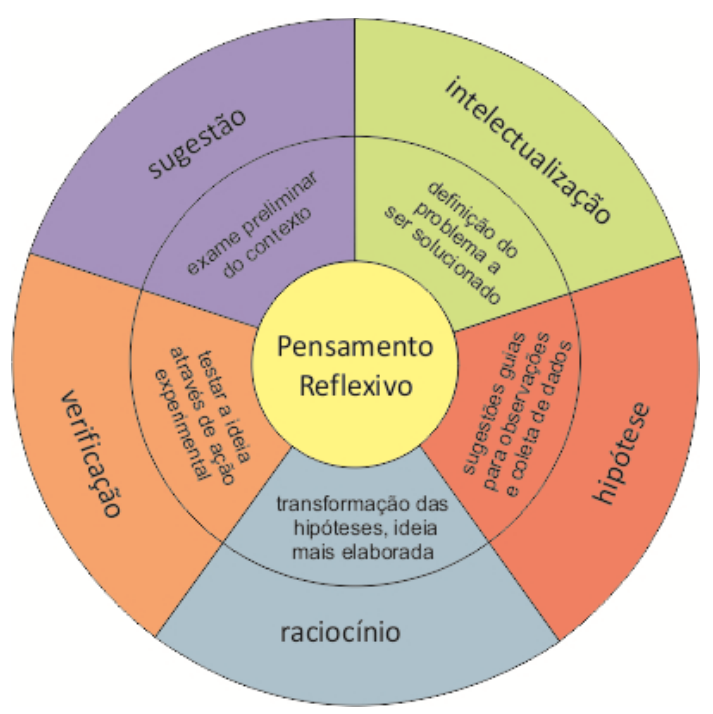

Figura 1 - Etapas do Pensamento Reflexivo. Fonte: Elaborado pelas autoras, com base na pesquisa realizada. 
A primeira fase, para esta descrição, é a sugestão. Nessa, ocorre um exame das condições, dos recursos, das dificuldades, antes de se definir o problema. A segunda é a intelectualização, em que o problema é de fato constituído e sua solução passa a ser requerida. Na terceira fase, titulada pelo autor como hipótese, surgem sugestões que passam a guiar a observação e outras operações durante a coleta dos fatos. Já na quarta fase, estabelece-se o raciocínio, em que a hipótese passa por transformações a partir da análise dos fatos e surge uma ideia mais elaborada para a solução do problema. Por último, a quinta fase é a verificação da hipótese pela ação, em que se coloca a ideia para solução em uma verificação experimental, mediante ação exterior ou imaginativa, para sua validação ou para uma nova adaptação (pode retornar para as fases anteriores). Ainda na fase final é importante inserir a reflexão, libertando a solução das influências cercantes dos sentidos e das tradições. Sendo essa a fase que verifica a hipótese através de uma ação experimental, fica evidente a importância da proximidade entre teoria e prática para construção do pensamento reflexivo. Essa proximidade evita o que Edgar Morin (2005) identifica como inteligência cega, aquela que isola todos os objetos do seu meio ambiente numa tentativa de simplificação que não corresponde à realidade.

Vale lembrar que a construção do pensamento reflexivo é individual e que, no meio acadêmico, aprender é uma iniciativa que cabe ao aluno. Nesse processo, o professor é "apenas" o guia da experiência rumo à aprendizagem. Porém, a forma de condução do processo deve ser bem planejada, para que cada aluno consiga construir o seu caminho/pensamento para formação de novos conhecimentos (Dewey, 1979).

Do mesmo modo que o pensamento reflexivo é necessário no processo de aprendizado pelo aluno, é importante para o ofício de professor. Através dessa lógica, é possível fortalecer, em cada um dos atores do processo de ensino-aprendizado, o sentido da autonomia.

Além disso, é preciso estabelecer diretrizes a uma didática que não ensine apenas os conteúdos, mas também ensine a pensar certo. Para pensar certo é necessário ter "mente aberta" e uma postura mais humana por parte dos professores, que evidencie o construir junto, pois quem "ensina aprende ao ensinar e quem aprende ensina ao aprender" (FREIRE, 2013, p.25). A aprendizagem valoriza-se por seu caráter transformador da realidade, onde o aluno percebe sua capacidade de adaptar, intervir e recriar o seu contexto.

Complementarmente, Dalben e Castro (2010, p.15) revelam que "a ação educativa se faz nas relações do homem com o mundo. $O$ ser humano, como ser que pensa e intencionalmente projeta suas ações, é capaz de criar metas a partir das experiências e interações vivenciadas no ambiente". Para o alcance dessa meta, Paulo Freire $(2013$, p.54) cita que também cabe ao educador estimular a curiosidade do aluno, à medida que a curiosidade é elemento base para produção de conhecimento, aliás, "a curiosidade é já conhecimento (...) e não só expressão dele".

Para Freire (2013, p. 04), o exercício da curiosidade requerer a conscientização, definida como "um dos caminhos para a posta em prática da curiosidade epistemológica" que, por sua vez, necessita de um processo de reflexão e verificação. A criatividade receberá a coerência realística e a oportunidade de averiguação à medida que há a aproximação do assunto abordado com a realidade acessível dos educandos. Além de estimular, essa estratégia reforça o caráter prático do conteúdo e as várias possibilidades de abordagem daquilo que já é identificado. 
Voltando tais conhecimentos para a realidade da Prática Projetual-I, os professores identificam que não se pode tratar o ensinar a projetar em design como uma transferência de informações de um ser cheio para um vazio. Esse é um processo de troca rica em percepções e conteúdos, favorecendo o conhecimento. É necessário criar contexto favorável a esse pensar reflexivo e ao exercício da autonomia, permitindo troca entre alunos e professores capaz de sensibilizar, otimizar a eficiência do trabalho, a identificação de oportunidades, o planejamento e a execução de soluções de design, num processo fluido e produtivo. Visto que, como nos diz Paulo Freire (2013, p. 24) "ensinar não é transferir conhecimento, mas criar as possibilidades para a sua produção ou a sua construção".

\section{UMA NOVA MANEIRA DE ENSINAR E APRENDER A PRÁTICA PROJETUAL EM DESIGN DE AMBIENTES}

A prática pedagógica proposta em 2012 aos alunos de design de ambientes teve, como objetivos, sensibilizar, conscientizar e capacitar os alunos para o desenvolvimento de soluções de design para ambientes diversos na cidade de Belo Horizonte. Para tanto, era necessário possibilitar o desenvolvimento de processo fluido da metodologia de projeto, o entendimento da abrangência da atuação do designer de ambientes e o desenvolvimento da capacidade de identificar possibilidades de um contexto projetual. Detalhe relevante a ser considerado neste momento é que o contexto de projeto não foi apresentado aos alunos, cabendo a eles identificar e prospectar oportunidades para proposição de soluções de design de ambientes.

Como estratégias, os professores identificaram a necessidade de instigar a curiosidade, criatividade e a capacidade investigativa. Para isso, era essencial que os alunos estabelecessem conexão com propósito entre diversas informações de diferentes áreas do saber, e que conquistassem coerência entre as etapas da metodologia de projeto de design.

Com base nessas diretrizes, as duas turmas do 30 período, turnos manhã e tarde, foram divididas, cada uma, em 10 grupos distintos, com a previsão de atividades individuais e coletivas.

As etapas do processo foram apresentadas de maneira gradativa, de modo que os alunos vivenciassem cada fase em sua plenitude, com percepção aguçada, exercitando a capacidade de organização, investigação, reflexão e criação. Tal estratégia teve como intensão contribuir para o prolongamento do estado de dúvida sugerido pelo pensamento reflexivo.

Na primeira etapa, baseada na fase de sugestão do pensamento reflexivo, a orientação dada pelos professores requeria a pesquisa de campo e a pesquisa aplicada como premissa para o projeto de design. As equipes foram orientadas a realizar visitas a locais ${ }^{6}$ determinados. Cada um dos grupos, compostos em média por quatro alunos, deveria se envolver com a observação desses lugares. Durante aproximadamente 180 minutos, os alunos trataram de observar e registrar individualmente a relação entre os indivíduos (público frequentador), os objetos e o espaço. Em seguida, os alunos deveriam se envolver, em grupo, com a análise e a síntese das observações, e elaborar

\footnotetext{
${ }^{6}$ Lugares determinados pelos professores para visita: Praça da Liberdade, BH Shoopping, Parque Municipal, Bar, Ônibus, Feira Hippie, Escola de Belas Artes, Biblioteca Universitária, Palácio das Artes e Rodoviária, todos localizados na cidade de Belo Horizonte, Minas Gerais.
} 
um retrato do público de interesse por meio do método personas ${ }^{7}$. Até então, os alunos são sabiam o que deveriam projetar. Sabiam, no entanto, a necessidade de entenderem o contexto para o qual a solução de design aconteceria num futuro breve.

Na segunda etapa, como consequência da fase anterior, os grupos analisaram e mapearam os desejos, necessidades e possibilidades do público observado. Para esse processo, foi solicitado que utilizassem painéis de estilo de vida, semântico e iconográfico. Caso fosse identificada a falta ou insuficiência de informações para essa intelectualização, o grupo deveria retomar a fase anterior complementando o embasamento necessário. Além disso, deveriam indicar possíveis demandas e construir o desafio projetual. Após a definição do desafio, as equipes foram orientadas a iniciar o trabalho de conceituação do projeto num contexto criativo, onde a liberdade para ideias (com auxílio de ferramentas como brainstorming e mapa mental) e a orientação metodológica caminharam juntas. A conceituação deveria ser pensada para o público específico de cada grupo e dentro do contexto observado, mesmo sem saber qual seria a sua aplicação prática. Como resultado, os conceitos gerados, além de coerentes, exprimiram ao máximo a essência dos personagens, o que facilitou a sua decodificação em diretrizes projetuais e posterior aplicação em projeto.

$\mathrm{Na}$ terceira etapa, os alunos foram surpreendidos com a informação do objeto de projeto, exigindo deles capacidade de reflexão, decisão e articulação. Conforme público de interesse determinado, contexto mapeado e conceito definido, cada grupo deveria propor solução projetual que provocasse experiência sensorial para o dia dos namorados. A aproximadamente um mês da data comemorativa, os grupos deveriam compatibilizar demandas, definir propósitos coerentes com o desafio projetual e viabilizar ideias através da construção de protótipos. A necessidade de adaptação foi evidente, assim como o imperativo de abandonar estereótipos e ideias preconcebidas.

Para pensarem nas possibilidades, os grupos, por iniciativa própria e assistidos pelos professores, propuseram novos brainstorming (agora focados na solução), criaram situações de uso e se envolveram com o processo de geração de alternativas. A definição da solução ficou condicionada, pelos professores, a fatores tais como o orçamento, a exequibilidade e a viabilidade técnica da ação, considerando o contexto real observado e documentado nas fases anteriores. Além disso, era primordial que a solução desenvolvida fosse vinculada ao conceito anteriormente definido por cada um dos grupos.

Durante o planejamento da "experiência", o grupo continuou a registrar as ideias no caderno de processos (anteriormente usado como caderno de anotações), organizando as ações e as etapas necessárias, dividindo as tarefas e desenvolvendo a linguagem desejada (diretrizes projetuais) e estratégias (efeitos). Os registros foram feitos por meio de croquis de produtos, de ambiências e da relação entre os elementos para alcançar o efeito desejado, representando a etapa de geração de alternativas. Foi possível perceber a preocupação dos alunos sobre como o público de interesse reagiria com as ideias. Os resultados dessa fase permitiram elucidar aos professores e alunos a importância do conceito e da relação entre as demais fases do processo.

\footnotetext{
${ }^{7}$ A ferramenta conhecida como personas (CYBIS et al., 2010), consiste na descrição de perfis de pessoas fictícias com base em informações qualitativas coletadas por meio de observações e entrevistas. Basicamente se constrói um personagem com a criação de um nome e a definição de foto, sexo, idade, estado civil, família, onde habita, grau de educação, trabalho, fatores de estilo de vida, objetivos, valores e postura.
} 
Por fim, na quarta e última etapa, os alunos deveriam verificar a ideia através de protótipo $^{8}$, cabendo também o registro e a apresentação gráfica da proposta projetual. Era preciso desmitificar a impossibilidade de construção de protótipos para solução de design para ambientes, ação muito comum para outros tipos de produtos do design e não explorada anteriormente nesta disciplina. Nesse sentido, os professores identificaram a prototipagem como estratégia para aproximar a ideia de uma realidade possível. Prototipar as ideias para os ambientes permitiu o contato dos alunos com a realidade das coisas (volumes, proporções, texturas, pesos, luzes, cheiros, dentre outros) além de tornar a solução mais passível de reflexão.

Após a vivência das "experiências", foi solicitado aos alunos que expressassem, no caderno de processos, as respectivas percepções sobre os pontos positivos e negativos da atividade. E, aproximadamente 18 meses após a atividade, foi solicitado $o$ mesmo a um dos grupos, instigados a refletir sobre o processo de aprendizagem por meio de grupo focal. De posse dos registros, que serviram para avaliar o processo de ensino, foram identificadas forças e fraquezas, possibilitando o aprimoramento da prática projetual para o curso de Design de Ambientes.

Cabe relatar que, a partir desse feedback dos alunos, foi possível reconhecer que a atividade conseguiu sensibilizá-los sobre as possibilidades da função social do designer de ambientes, bem como da abrangência da influência do ambiente no comportamento dos indivíduos.

Compreenderam a importância de pesquisar, entender, ler e dominar os assuntos em questão para fundamentar as decisões de projeto, contribuindo para a assertividade da solução e sua coerência com o contexto projetual. Além disso, vivenciaram a importância de se buscar referências em outras áreas do saber e de ampliar o repertório, atitude que deve ser inerente ao trabalho do designer.

Perceberam o quanto um trabalho colaborativo é enriquecedor, na medida em que cada integrante do grupo pôde contribuir com as suas sugestões e habilidades. No que se refere à organização, entenderam a importância de se planejar e distribuir tarefas conforme a potencialidade e aptidão de cada um. Identificaram também o desenvolvimento de conduta empreendedora e a importância da representação de croquis e desenhos técnicos para a comunicação com o grupo e para a execução da solução.

A possibilidade de prototipar a solução serviu como impulso para os trabalhos e como fator importante para aproximar a ideia à realidade através de verificação prática.

\section{CONSIDERAÇÕES FINAIS}

Acredita-se que o olhar do futuro designer de ambientes deva ser estimulado por desafios, pelo experimentar de questões que exercitem o pensar, o examinar, o raciocinar, o sugerir, e o verificar, para que esteja apto a projetar ambientes eficientes e que promovam o bem-estar na vida das pessoas.

\footnotetext{
${ }^{8}$ Baxter (2000, p. 243-244) revela que "tendo-se alcançado uma solução para a configuração do produto, é necessário verificar se essa solução atende aos objetivos propostos. Para isto é necessário construir e testar o protótipo do novo produto." Considerando o ambiente como um produto do processo de design, possível de ser produzido ou reproduzido conforme especificações e determinações projetuais, coube às equipes envolvidas na atividade seguir a orientação desse autor para a prototipagem das ideias: "desenvolva protótipo com o mínimo grau de complexidade e sofisticação, o necessário apenas para você obter a resposta que procura".
} 
A experiência descrita neste artigo clarifica sobre a importância dos professores periodicamente revisarem suas práticas, ou seja, saírem da chamada "zona de conforto" e inovarem em suas práticas pedagógicas e recursos didáticos.

A atual geração de alunos universitários, em especial os da Escola de Design, se mostra receptiva a novas ideias, ao desafio, ao vínculo com a sua realidade e a vivência de experiências que estimulem o seu crescimento. Um novo jeito de pensar que implica novas maneiras de ensinar e aprender.

Planejar, aplicar, revisar e avaliar sua própria prática pedagógica é um ato que deveria ser adotado por todos os professores e, em especial, os de design, sob a premissa que os designers - alunos e professores - devem estar atentos às mudanças de comportamento, desejos e possibilidades nos diversos lugares da vida cotidiana, o que logicamente, no contexto universitário, indica novas práticas pedagógicas e diversificação dos recursos didáticos como premissa para avanços no ensino e aprendizado do design.

\section{REFERÊNCIAS}

BAXTER, Mike. Projeto de produto: guia prático para o design de novos produtos. $2^{a}$ Ed. São Paulo: Editora Blücher, 2005.

BÜRDEK, Bernhard E. História, teoria e prática do design de produtos. São Paulo: Edgard Blücher. 2006.

CARDOSO, Rafael. Design para um mundo complexo. São Paulo: Cosac Naify, 2012.

CYBIS, Walter; BETIOL, Adriana Holtz; FAUST, Richard. Ergonomia e usabilidade: conhecimentos, métodos e aplicações. 2a Ed. São Paulo: Novatec, 2010.

DALBEN, Ângela Imaculada Loureiro de Freitas; CASTRO, Elza Vidal de. A relação pedagógica no processo escolar: sentidos e significados. In: TEIXEIRA, Adla Betsaida Martins. (Org.). Temas Atuais em Didática. Belo Horizonte: Editora UFMG, 2010.

DEWEY, John. Como pensamos: como se relaciona o pensamento reflexivo com o processo educativo, uma reexposição. Tradução de Haydée Camargos Campos. 3a $\mathrm{Ed}$. São Paulo: Nacional, 1979.

ESCOLA DE DESIGN da Universidade do Estado de Minas Gerais (ED/UEMG). Projeto Pedagógico: Curso de Design de Ambientes. Belo Horizonte, 2003.

FREIRE, Paulo. Pedagogia da autonomia: saberes necessários à prática educativa. 46ạ Ed. Rio de Janeiro: Paz e Terra, 2013.

LÖBACH, Bernd. Design Industrial: bases para configuração dos produtos industriais. Tradução de Freddy Van Camp. São Paulo: Edgard Blucher, 2001.

MACHADO, Nilson José. Sobre a ideia de competência. In.: PERRENOUD, Philippe et al.; As competências para ensinar no século XXI - formação dos professores e o desafio da avaliação. Porto Alegre: ARTMED, 2002.

MORIN, Edgar. Introdução ao pensamento complexo. Porto Alegre: Sulina, 2006.

MUNARI, Bruno. Das coisas nascem as coisas. 2ª Ed. São Paulo: Martins Fontes, 2008. 
THIOLLENT, Michel. Metodologia da pesquisa-ação. São Paulo: Cortez, 1996.

TRIPP, David. Pesquisa-ação: uma introdução metodológica. Educação e Pesquisa, v. 31, n. 3, p. 443-466, set./dez. 2005.

UNESCO. Educação. Um tesouro a descobrir. Relatório para a UNESCO da Comissão Internacional sobre educação para o século XXI. Brasília, 2010. (Título original: Learning: the treasure within; report to UNESCO of the International Commission on Education for the Twenty-first Century (highlights). Paris: UNESCO, 1996). 